\title{
Fucoidan inhibits epithelial-to-mesenchymal transition via regulation of the HIF-1 $\alpha$ pathway in mammary cancer cells under hypoxia
}

\author{
WEIWEI LI ${ }^{1}$, DINGSHAN XUE ${ }^{2}$, MEILAN XUE ${ }^{1}$, JINGLAN ZHAO $^{3}$, HUI LIANG $^{4}$, YING LIU $^{1}$ and TING SUN ${ }^{1}$ \\ ${ }^{1}$ Department of Biochemistry and Molecular Biology, Basic Medical College, Qingdao University of Medicine, Qingdao, \\ Shandong 266021; ${ }^{2}$ Department of Senior Grade Three, Qingdao West Coast District No. 1 Senior High School, Qingdao, \\ Shandong 266555; ${ }^{3}$ Department of Cardiothoracic Surgery of Qingdao Center Medical Group, Qingdao, Shandong 266042; \\ ${ }^{4}$ The Institute of Human Nutrition, Qingdao University of Medicine, Qingdao, Shandong 266021, P.R. China
}

Received April 1, 2018; Accepted March 7, 2019

DOI: $10.3892 / \mathrm{ol} .2019 .10283$

\begin{abstract}
This study examined the effects of fucoidan on epithelial-to-mesenchymal transition (EMT) in a human triple-negative breast cancer (TNBC) cell line in a hypoxic microenvironment. Transwell and wound-healing assays were performed to analyze the invasion and migration of MDA-MB-231 human mammary cancer cells, respectively. The expression levels of EMT markers and hypoxia-inducible factor- $1 \alpha$ (HIF-1 $\alpha)$ were detected through western blotting. Under hypoxia, fucoidan treatment inhibited proliferation of breast cancer cells. Fucoidan also suppressed the invasion and migration of MDA-MB-231 cells. Western blotting revealed that fucoidan treatment significantly reduced the protein expression levels of HIF-1 $\alpha$ and HIF-1 target genes. Furthermore, the nuclear translocation and activity of HIF-1 $\alpha$ were reduced. Fucoidan treatment significantly downregulated the expression levels of mesenchymal markers (N-cadherin and vimentin), but upregulated the expression levels of the epithelial markers zonula occludens-1 and E-cadherin. In addition, overexpression of HIF1- $\alpha$ protected cells from fucoidan-mediated suppression of migration and invasion. These data suggested that fucoidan may inhibit EMT in human TNBC cells via downregulation of the HIF1- $\alpha$ signaling pathway.
\end{abstract}

\section{Introduction}

A hypoxic microenvironment is a common characteristic of solid tumors. It has been reported that hypoxia can

Correspondence to: Professor Meilan Xue, Department of Biochemistry and Molecular Biology, Basic Medical College, Qingdao University of Medicine, 38 Dengzhou Road, Qingdao, Shandong 266021, P.R. China

E-mail: snowml@126.com

Key words: fucoidan, epithelial-to-mesenchymal transition, hypoxia-inducible factor-1 $\alpha$, triple-negative breast cancer induce epithelial-to-mesenchymal transition (EMT) via hypoxia-induced factor- $1 \alpha$ (HIF-1 $\alpha$ ) in various types of cancer, including gastric cancer, hepatoblastoma, pancreatic carcinoma, colon carcinoma and mammary cancer (1-3). EMT is an important process in cancer metastasis; during EMT, epithelial cells lose their cell polarity and cell-cell adhesion, and gain migratory and invasive properties to become mesenchymal stem cells. To complete the metastatic process, cancer cells must migrate out of the primary tumor. Studies in mammary cancer have shown that the EMT phenomenon increases the migration and invasion of cancer cells, and is closely associated with tumor occurrence, infiltration and distant implantation $(4,5)$. Cancer cells must detach from the neighboring epithelial cells by reducing E-cadherin expression to start invading the surrounding extracellular matrix. It has been reported that HIF-1 $\alpha$ expression is rarely observed in normal tissues but is increased in various cancer tissues or cells, and is closely associated with the migration and invasion of tumor cells. Therefore, inhibition of HIF-1 $\alpha$ activation may reduce the development and progression of tumors (6-8).

HIF-1 $\alpha$ can directly or indirectly regulate EMT regulators, including TWIST, Snail, carbonic anhydrase IX (CAIX), glucose transporter protein-1 (GLUT-1), and other transcription factors (9-11). These transcription factors then transactivate EMT-related genes, including vimentin, E-cadherin and $\mathrm{N}$-cadherin, to regulate progression of the EMT $(12,13)$. HIF-1 $\alpha$ levels in mammary cancer tissues are associated with pathological stages, and high HIF-1 $\alpha$ levels may result in high multiplication rates and the formation of more aggressive tumors (14).

The metastasis of triple-negative breast cancer (TNBC) is associated with poor prognosis and high mortality due to ineffective treatment. Fucoidan is a complex sulfated polysaccharide extracted from brown seaweed. It has been reported to exert antitumor activity in various types of cancer, including acute prostate cancer cells, myeloid leukemia, lung cancer and hepatocellular carcinoma cells (15-18). Our previous study reported that fucoidan induces apoptosis of different breast cancer cell lines, including mouse breast cancer 4T1 cells, human breast cancer MCF-7 cells and MDA-MB-231 
cells (19-21). However, the effects of fucoidan on the metastasis of TNBC and the underlying mechanisms remain elusive. The present study aimed to examine the effects of fucoidan on EMT and the underlying molecular mechanisms in a TNBC cell line. Since hypoxia may promote EMT in mammary cancer cells via regulation of the expression of EMT regulators, the present study also aimed to clarify whether fucoidan can directly affect HIF-1 $\alpha$ in a TNBC cell line.

\section{Materials and methods}

Materials. Fucoidan was obtained from Sigma-Aldrich (Merck KGaA, Darmstadt, Germany). It was dissolved in normal saline at a concentration of $20 \mathrm{mg} / \mathrm{ml}$ and then stored at $-20^{\circ} \mathrm{C}$. A human mammary cancer cell line (MDA-MB-231) was purchased from the Cell Bank of the Shanghai Institute of Cell Biology (Shanghai, China). RPMI-1640 medium was obtained from HyClone (GE Healthcare Life Sciences; Logan, UT, USA) and was supplemented with $1 \%$ penicillin/streptomycin and $10 \%$ fetal bovine serum (FBS; Gibco; Thermo Fisher Scientific, Inc., Waltham, MA, USA). Antibodies against CAIX (cat. no. A1463-100), HIF-1 $\alpha$ (cat. no. TA301442), vimentin (cat. no. 3634-100), N-cadherin (cat. no. 119-14215) and histone H3 (cat. no. A310-257A) were obtained from Abcam (Cambridge, MA, USA). Antibodies against zonula occludens-1 (ZO-1, cat. no. sc-33725), E-cadherin (cat. no. sc-71008), TWIST (cat. no. sc-81417), Snail (cat. no. sc-393172), GLUT-1 (cat. no. sc-377228), Na, K-ATPase (cat. no. sc-71638) and $\beta$-actin (cat. no. sc-70319) were purchased from Santa Cruz Biotechnology, Inc. (Dallas, TX, USA). Secondary anti-rabbit (cat. no. sc-2491) and anti-mouse (cat.no. sc-516102) antibodies were obtained from Santa Cruz Biotechnology, Inc.

Cell culture. MDA-MB-231 cells were cultured in Roswell Park Memorial Institute 1640 medium (Hyclone; GE Healthcare Life Sciences, Logan, UT, USA), supplemented with $10 \%$ heat-inactivated FBS (Gibco; Thermo Fisher Scientific, Inc., Waltham, MA, USA) and 1\% penicillin/streptomycin at $37^{\circ} \mathrm{C}$ in a humidified atmosphere containing $5 \% \mathrm{CO}_{2}$, and were allowed to attach onto the dish. All cells were cultured to $\sim 90 \%$ confluence in 6-well plates prior to treatment. A hypoxic humidified incubator with a gas mixture of $94 \% \mathrm{~N}_{2}, 5 \% \mathrm{CO}_{2}$ and $1 \% \mathrm{O}_{2}$ was used for hypoxia exposure. All cells were incubated under hypoxia during or after fucoidan treatment.

MTT assay. MTT (Sigma-Aldrich; Merck KGaA) was used for the cell proliferation assay. Each well of a 96-well plate was seeded with $1 \times 10^{4}$ cells $/ \mathrm{ml}$. After overnight incubation at $37^{\circ} \mathrm{C}$, a total of $6.25,12.5$ or $25 \mu \mathrm{g} / \mathrm{ml}$ fucoidan was added to the breast cancer cells. The plates were incubated in a hypoxic chamber at $37^{\circ} \mathrm{C}$. Following incubation for 24,48 or $72 \mathrm{~h}$, $20 \mu \mathrm{l} \mathrm{MTT}$ reagent was added to all wells at a concentration of $5 \mathrm{mg} / \mathrm{ml}$ at $37^{\circ} \mathrm{C}$ for $4 \mathrm{~h}$, and the crystals were dissolved in DMSO. The absorbance was detected at $490 \mathrm{~nm}$ on an ELISA reader (BioTek Instruments, Inc., Winooski, VT, USA).

Wound-healing assay. Breast cancer cells were grown until confluent in 6-well plates. Following treatment with fucoidan $(0,6.25,12.5$ or $25 \mu \mathrm{g} / \mathrm{ml})$ for $24 \mathrm{~h}$ in a hypoxic chamber, the cell monolayers were scratched using a sterile $200 \mu \mathrm{l}$ plastic pipette tip. Following aspiration of the medium, the displaced cells were washed with PBS. Subsequently, the cells were continuely incubated in a hypoxic chamber for $24 \mathrm{~h}$. Five images were captured from randomly selected microscope fields at different time points using an OLYMPUS CX31 microscope (Tokyo, Japan). The area of the wound was measured using ImageJ 1.51p software (National Institutes of Health, Bethesda, MD, USA).

Transwell invasion assay. For the invasion assay, 24-well Transwell units were used. The lower units of a $6.5-\mathrm{mm}$ Transwell filter with $0.4 \mu \mathrm{m}$ pore size were precoated with Matrigel (BD Biosciences, San Jose, CA, USA). Following treatment with fucoidan $(0,6.25,12.5$ or $25 \mu \mathrm{g} / \mathrm{ml})$ for $24 \mathrm{~h}$ in a hypoxic chamber, the cancer cells were suspended in serum-free medium, and $1 \times 10^{4}$ cells were seeded onto the upper wells. The lower units were filled with medium containing $10 \%$ FBS as a chemoattractant. After incubation in a hypoxic chamber for $12 \mathrm{~h}$, the cancer cells on the upper units of the membrane were removed using a cotton swab. The invading cells on the bottom surface of the membrane were fixed with $70 \%$ ethanol for $10 \mathrm{~min}$. After staining with $0.1 \%$ crystal violet for $10 \mathrm{~min}$ at room temperature, the cells were counted using an OLYMPUS CX31 microscope.

HIF-1 activation assay. MDA-MB-231 cells treated with fucoidan $(0,6.25,12.5$ or $25 \mu \mathrm{g} / \mathrm{ml})$ for $48 \mathrm{~h}$ in a hypoxic chamber were washed with PBS. HIF-1 $\alpha$ activation was evaluated using a HIF-1 activation assay kit (cat. no. 47096; Active Motif, Carlsbad, CA, USA), according to the manufacturer's protocols. Finally, the absorbance was detected at $450 \mathrm{~nm}$ with a SpectraMax 190 plate reader (Molecular Devices, LLC, Sunnyvale, CA, USA).

Overexpression of $H I F-1 \alpha$. Breast cancer cells were transfected with HIF-1 $\alpha$ overexpression vector (HIF-1 $\alpha$-pcDNA3.0; Shanghai Genechem Co., Ltd., Shanghai, China) or empty plasmid (pcDNA3.0; Shanghai Genechem Co., Ltd.) using Lipofectamine ${ }^{\circledR} 2000$ (Invitrogen, Thermo Fisher Scientific, Inc.), according to the manufacturer's protocols. Briefly, the cells were prepared into a single cell suspension with $0.2-1 \times 10^{6} / \mathrm{ml}$ density by trypsin digestion and then inoculated into the 6-well plate. The transfection was conducted when the cells had reached 90-95\% confluence. Each well contained $4 \mu \mathrm{g}$ plasmid and $10 \mu 1$ Lipofectamine ${ }^{\circledR} 2000$. The follow-up experiments were continued $24 \mathrm{~h}$ after transfection. The sequence information of overexpression vector was shown in Fig. 1.

Western blotting. Nuclear extracts, cytosolic extracts and membrane extracts were prepared using the Nuclear and Cytoplasmic Protein Extraction Kit and Membrane and Cytosol Protein Extraction kit (Beyotime Institute of Biotechnology, Shanghai, China). The membrane protein samples were used to detect the levels of ZO-1 and E-cadherin, and Na, K-ATPase was used as a reference for determination. The cytoplasmic protein samples were used to detect the expression levels of vimentin, TWIST, Snail, CAIX, N-cadherin and GLUT-1, and $\beta$-actin was used as a reference for determination. The 


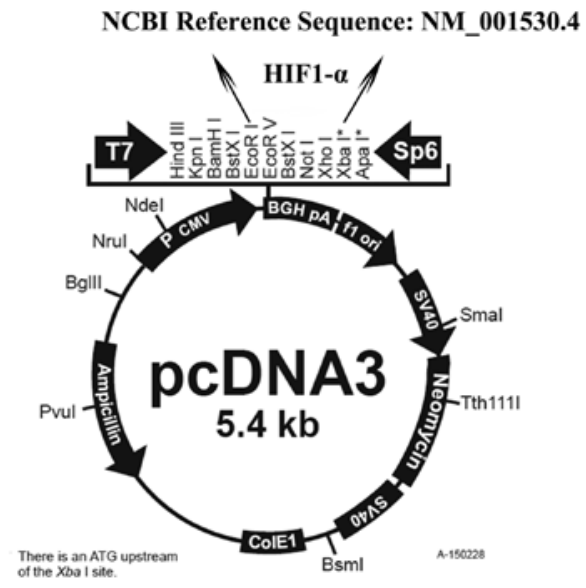

Figure 1. Sequence information of the overexpression vector HIF-1 $\alpha$ pcDNA3.0. HIF-1 $\alpha$ (NCBI Reference Sequence, NM_001530.4) was inserted between the EcoRI and $\mathrm{XbaI}$ restriction sites. HIF-1 $\alpha$, hypoxia-inducible factor-1 $\alpha$.

nuclear protein samples were used to detect HIF-1 $\alpha$ levels, and histone $\mathrm{H} 3$ was used as a reference.

The total protein concentrations were determined using a BCA protein assay kit (Beyotime Institute of Biotechnology). Each protein sample $(30 \mu \mathrm{g})$ was separated by SDS-PAGE (9\% gel) and then transferred to nitrocellulose (NC) membranes, which were obtained from Beijing Solarbio Science \& Technology Co., Ltd. (Beijing, China). After blocking with 5\% non-fat dry milk in Tris-buffered saline with Tween-20 buffer (TBST; $20 \mathrm{mM}$ Tris-HCl, $120 \mathrm{mM} \mathrm{NaCl}, 0.1 \%$ Tween-20) at room temperature for $1 \mathrm{~h}$, the $\mathrm{NC}$ membranes were incubated with primary antibodies at $4^{\circ} \mathrm{C}$. The dilution ratio for anti-ZO-1, anit-vimentin and anti-E-cadherin was 1:1,000. The dilution ratio for anti-TWIST, anti-Snail, anti-CAIX, anti-N-cadherin and anti-GLUT-1 was 1:200. The dilution ratio for anti-HIF- $1 \alpha$, anti-Na, K-ATPase, anti- $\beta$-actin and anti-Histone $\mathrm{H} 3$ was 1:500. Following overnight incubation, the NC membranes were washed three times with TBST for $10 \mathrm{~min}$ and were then incubated with the corresponding secondary antibodies (dilution, 1:80) at room temperature for $1 \mathrm{~h}$. After washing, protein bands were visualized by enhanced chemiluminescence with a reagent containing the horseradish peroxidase (HRP) substrate luminol, which was obtained from EMD Millipore (Billerica, MA, USA). Protein expression was quantified using Gel-Pro Analyzer 3.1 software (Media Cybernetics, Inc., Rockville, MD, USA).

Reverse transcription-quantitative polymerase chain reaction $(R T-q P C R)$. Total RNA in cells after transfection was extracted using an RNAprep pure tissue kit (Tiangen Biotech Co., Ltd., Beijing, China). cDNA was synthesized by RT using $200 \mathrm{ng}$ total RNA. Each $20 \mu \mathrm{l}$ RT reaction was performed using a miScript II Reverse Transcriptase kit (Qiagen GmbH, Hilden, Germany) according the manufacturer's protocol in a GeneAmp PCR system 9700 (Applied Biosystems; Thermo Fisher Scientific, Inc.) for $60 \mathrm{~min}$ at $37^{\circ} \mathrm{C}$, followed by heat inactivation of the RT for 5 min at $95^{\circ} \mathrm{C}$. The cDNA was then subjected to RT-qPCR amplification on a LightCycler 480 RT PCR system (Roche Diagnostics, Basel, Switzerland). The RT PCR Master mix

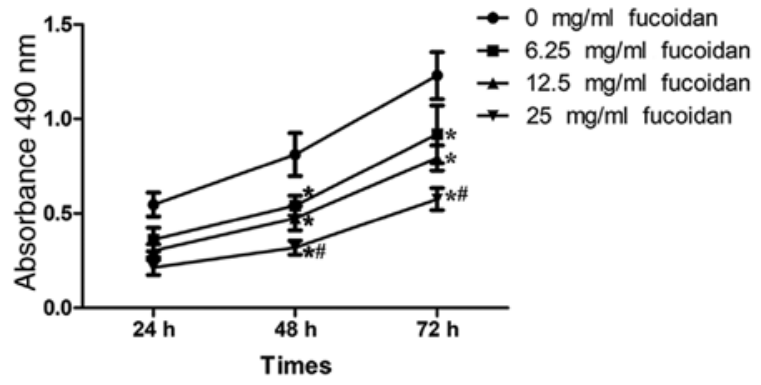

Figure 2. Effect of fucoidan treatment on the proliferation of MDA-MB-231 cells under hypoxia. The effects of fucoidan on the proliferation of breast cancer cells under hypoxia were detected via MTT assay. Fucoidan treatment inhibited the proliferation of MDA-MB-231 cells $(\mathrm{P}<0.05)$. Following treatment with $25 \mu \mathrm{g} / \mathrm{ml}$ fucoidan for $72 \mathrm{~h}$, cell proliferation declined by $53.2 \%$. Data are presented as the means \pm standard deviation. ${ }^{*} \mathrm{P}<0.05$ vs. control (0 $\mu \mathrm{g} / \mathrm{ml}$ fucoidan); ${ }^{~} \mathrm{P}<0.05 \mathrm{vs} .6 .25 \mu \mathrm{g} / \mathrm{ml}$ fucoidan.

(Takara Biotechnology Co., Ltd., Dalian, China) and specific primer/probe sets were used to amplify HIF-1 $\alpha$ and GAPDH (TaqMan Gene Expression Assays; Applied Biosystems; Thermo Fisher Scientific, Inc.). The following primer pairs were used for qPCR: HIF-1 $\alpha$, forward, 5'-CCTGAGCCT AATAGTCCC-3', reverse, 5'-GCTGGCATTAGCAGT AGG-3'; and GAPDH, forward, 5'-ATTCCATGGCACCGT CAAGGC T-3' and reverse, 5'-TCAGGTCCACCACTGACA CGT T-3' (designed by Takara Biotechnology Co. Ltd.). The amplification consisted of $95^{\circ} \mathrm{C}$ for $30 \mathrm{sec}$ and 40 cycles of $95^{\circ} \mathrm{C}$ for $5 \mathrm{sec}, 60^{\circ} \mathrm{C}$ for $30 \mathrm{sec}$, and $72^{\circ} \mathrm{C}$ for $2 \mathrm{~min}$ followed by a final extension at $72^{\circ} \mathrm{C}$ for $5 \mathrm{~min}$. The expression levels of each gene were normalized to GAPDH expression levels using the $2^{-\Delta \Delta \mathrm{Cq}}$ method as previously described (22).

Statistical analysis. All results are expressed as the means \pm standard deviation. Each experiment was repeated three times. Statistical analysis was performed using SPSS software (version 17; SPSS, Inc., Chicago, IL, USA). One-way analysis of variance was used to determine the statistical significance and Tukey's post hoc test was used to analyze the differences between two groups. $\mathrm{P}<0.05$ was considered to indicate a statistically significant difference.

\section{Results}

Fucoidan treatment inhibits the proliferation of MDA-MB-23I cells under hypoxia. The effect of fucoidan on the proliferation of breast cancer cells under hypoxia was determined using an MTT assay. Fig. 2 indicated that fucoidan treatment reduced the proliferation of breast cancer cells $(\mathrm{P}<0.05)$. Following treatment with fucoidan at a concentration of $25 \mu \mathrm{g} / \mathrm{ml}$ for $72 \mathrm{~h}$, the cell proliferation had declined by $53.2 \%$.

Fucoidan inhibits the migration and invasion of breast cancer cells. Wound-healing and Matrigel-coated Transwell invasion assays were used to detect whether fucoidan intervention exhibited any effect on EMT in MDA-MB-231 cells. As shown in Fig. 3A, fucoidan treatment reduced the migratory ability of breast cancer cells $(\mathrm{P}<0.001)$. Following treatment with fucoidan at a concentration of 12.5 or $25 \mu \mathrm{g} / \mathrm{ml}$ for $24 \mathrm{~h}$, cell invasion was also inhibited (Fig. 3B). 
A
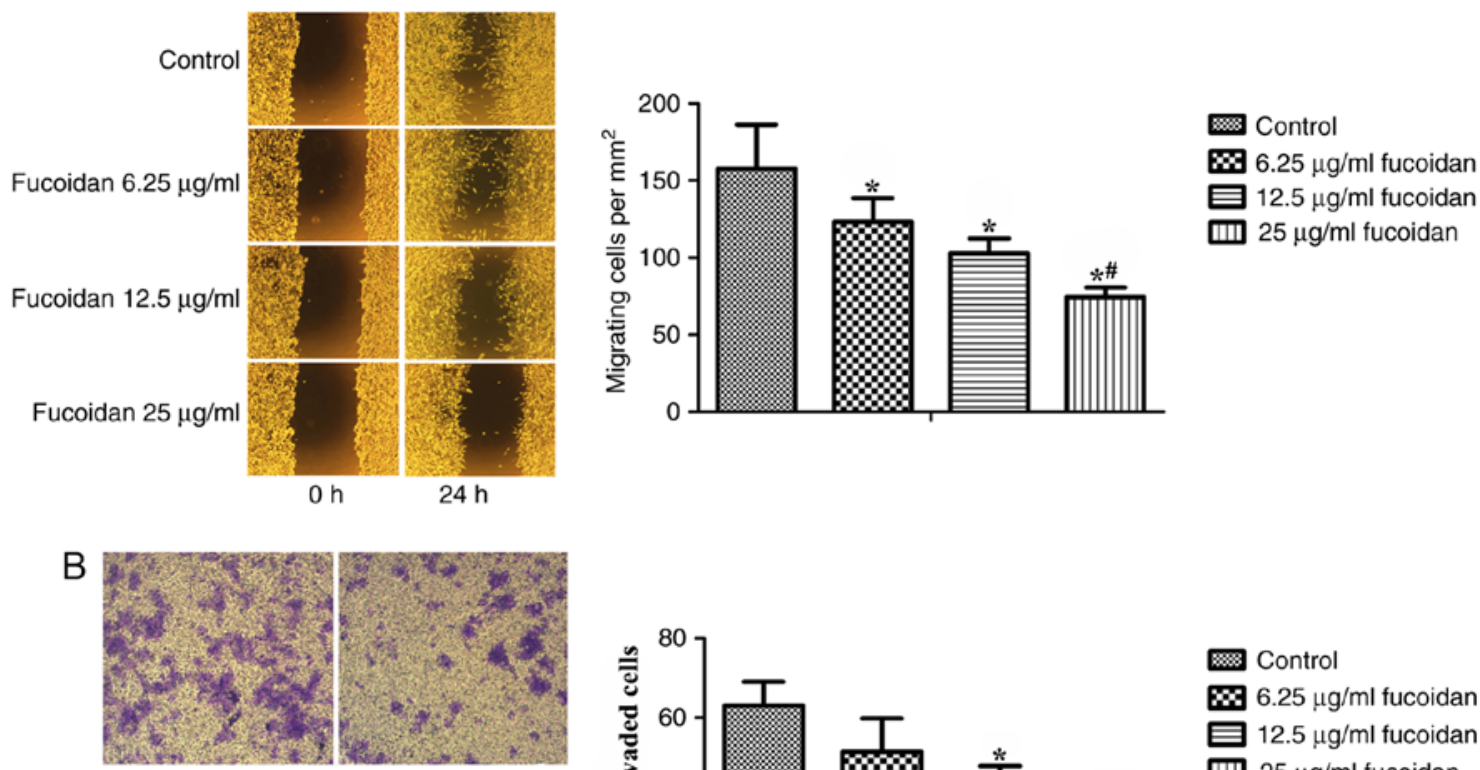
Control Fucoidan $6.25 \mu \mathrm{g} / \mathrm{m}$
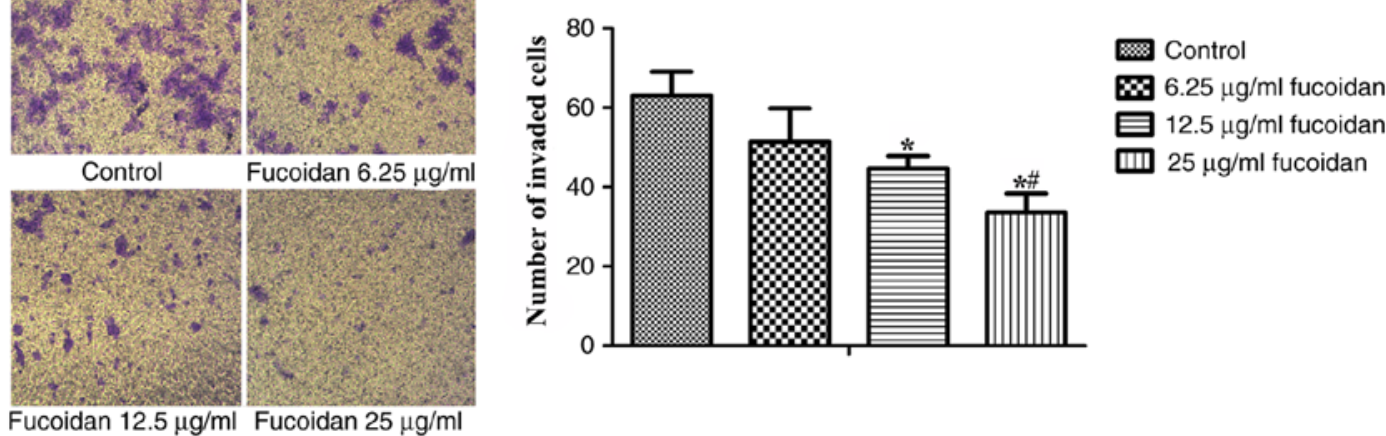

Figure 3. Fucoidan inhibits the migration and invasion of breast cancer cells. (A) A scratch assay was used to determine the migratory ability of breast cancer cells. Under a microscope, the relative wound closure was detected and images were captured (magnification, x100). Cell motility was quantified based on the wound width. Fucoidan treatment inhibited the migratory ability of breast cancer cells $(\mathrm{P}<0.001)$. (B) Transwell assays were used to determine the invasive ability of MDA-MB-231 cells. Representative fields showing invasive cells on the membrane are presented (magnification, x200). Following treatment with 12.5 or $25 \mu \mathrm{g} / \mathrm{ml}$ fucoidan, cell migration was inhibited. All experiments were repeated three times. Data are presented as the means \pm standard deviation. ${ }^{*} \mathrm{P}<0.05$ vs. control; ${ }^{\#} \mathrm{P}<0.05$ vs. $6.25 \mu \mathrm{g} / \mathrm{ml}$ fucoidan.

Fucoidan affects the expression levels of EMT markers. The results revealed that fucoidan treatment downregulated the expression levels of the mesenchymal markers $\mathrm{N}$-cadherin and vimentin (Fig. 4). In the membranes of MDA-MB-231 cells, the epithelial markers ZO-1 and E-cadherin were rarely expressed, but following treatment with fucoidan, the expression levels of ZO-1 and E-cadherin were significantly increased.

Fucoidan inhibits protein accumulation in the nucleus and activation of HIF-l $\alpha$. The effects of fucoidan on the expression and nuclear translocation of HIF-1 $\alpha$ were assessed by western blotting. The nuclear protein levels of HIF-1 $\alpha$ were decreased following treatment with fucoidan under hypoxic conditions (Fig. 5A). The activation of HIF-1 $\alpha$ was also assessed. As shown in Fig. 5B, fucoidan treatment decreased the activation of HIF-1 $\alpha$.

Fucoidan downregulates the expression of HIF-1 $\alpha$ target genes. HIFs can regulate the expression of numerous genes involved in tumor growth, metastasis and metabolic reprogramming $(23,24)$. HIF-1 $\alpha$ can directly or indirectly regulate the EMT regulators TWIST, Snail, CAIX and GLUT-1 (9-11). The expression levels of TWIST, Snail, CAIX and GLUT-1 were detected by western blotting. As shown in Fig. 6, following treatment with fucoidan, the expression levels of TWIST-1, Snail, CAIX and GLUT-1 were inhibited.
Overexpression of HIF-1 $\alpha$ results in the reversal of fucoidan-mediated suppression of cell migration and invasion. MDA-MB-231 cells were transfected with HIF-1 $\alpha$ overexpression plasmid (HIF-1 $\alpha$-pcDNA3.0) to determine whether the anti-EMT effects of fucoidan depended on HIF-1 $\alpha$; empty plasmid (pcDNA3.0) was used as a control. The expression of HIF- $1 \alpha$ and its target genes (TWIST and Snail) in MDA-MB-231 cells was increased by HIF-1 $\alpha$-pcDNA3.0 transfection (Fig. 7A). The mRNA expression levels of HIF-1 $\alpha$ in breast cancer cells were measured by RT-qPCR. Post-transfection with HIF-1 $\alpha$-pcDNA3.0, the mRNA expression levels of HIF-1 $\alpha$ were increased (Fig. 7B). Post-transfection with HIF-1 $\alpha$-pcDNA3.0, breast cancer cells were incubated with $25 \mu \mathrm{g} / \mathrm{ml}$ fucoidan, and cell invasion and migration were detected. Wound-healing and Matrigel-coated Transwell invasion assays revealed that overexpression of HIF-1 $\alpha$ resulted in the reversal of fucoidan-mediated suppression of cell migration and invasion (Fig. 7C and D).

\section{Discussion}

The present study demonstrated that fucoidan treatment inhibited the proliferation of breast cancer cells, and suppressed the migration and invasion of mammary cancer cells in a hypoxic microenvironment. The nuclear translocation and activity of HIF-1 $\alpha$ were also reduced by fucoidan. In addition, fucoidan significantly downregulated the expression 


\section{Cytoplasmic}
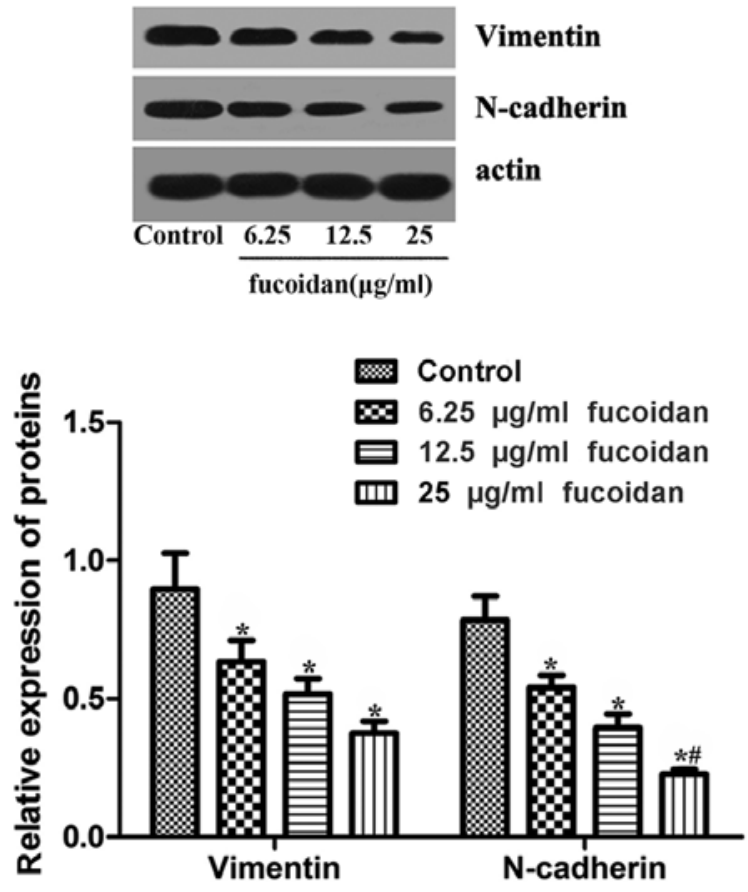
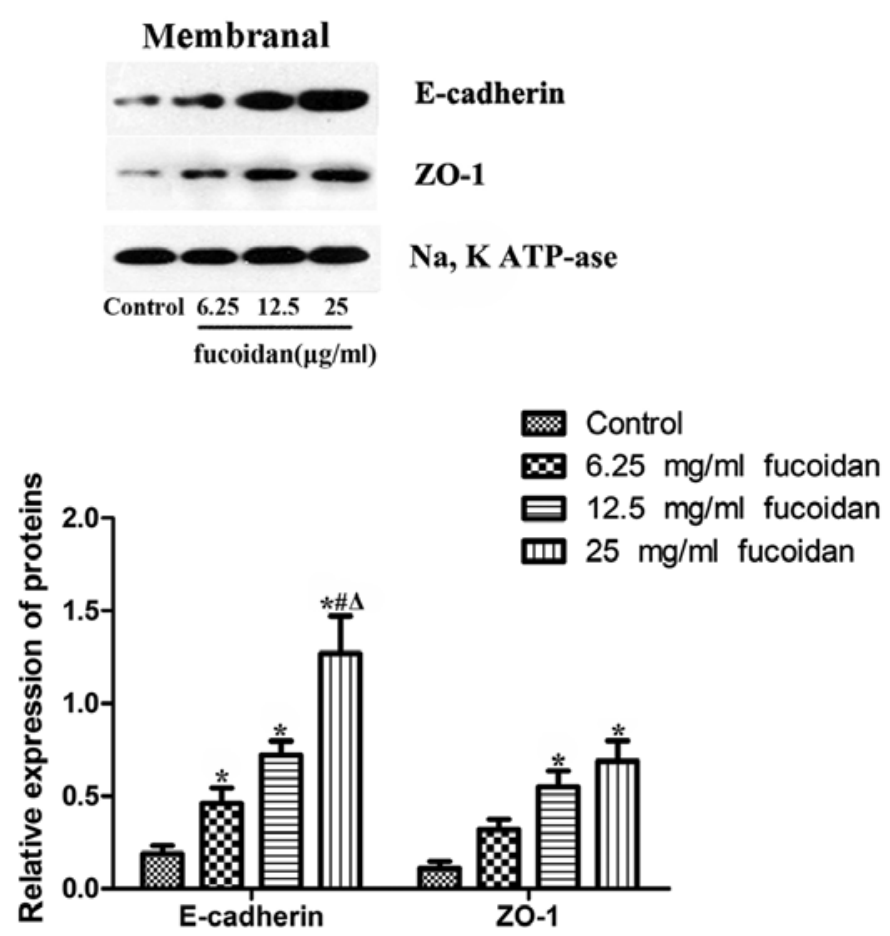

Figure 4. Effects of fucoidan on the expression levels of EMT markers. Following treatment with fucoidan, membrane and cytosolic extracts were prepared to measure the expression levels of EMT markers by western blot analysis. Fucoidan treatment significantly upregulated the expression levels of the epithelial markers ZO-1 and E-cadherin, but downregulated the expression levels of mesenchymal markers (N-cadherin and vimentin). All experiments were repeated three times. Data are presented as the means \pm standard deviation. ${ }^{*} \mathrm{P}<0.05$ vs. control; ${ }^{\#} \mathrm{P}<0.05 \mathrm{vs} .6 .25 \mu \mathrm{g} / \mathrm{ml}$ fucoidan; ${ }^{\Delta} \mathrm{P}<0.05 \mathrm{vs}$. $12.5 \mu \mathrm{g} / \mathrm{ml}$ fucoidan. ZO-1, zonula occludens-1.

levels of N-cadherin and vimentin, but upregulated ZO-1 and E-cadherin expression.

During the process of EMT, cancer cells lose the characteristics of epithelial cells, such as polarity and cell adhesion. Subsequently, cancer cells acquire a mesenchymal cell-like morphology and a migratory ability. Once cancer cells cease to express epithelial markers, including E-cadherin (an adherens junction protein), they initiate the expression of mesenchymal markers, including $\mathrm{N}$-cadherin and vimentin (25). ZO-1 is another epithelial marker and is a submembrane scaffolding protein. When ZO-1 relocates into the cell from tight junctions, it may promote the invasion activity (26).

HIFs are critical transcription factors that can regulate adaptive cellular responses to low $\mathrm{O}_{2}$ concentrations in Metazoa. HIFs have been reported to be upregulated in various cancer cells under hypoxia, which is commonly found in tumor microenvironments $(23,24)$.

HIF-1 has two subunits, the HIF- $1 \alpha$ and HIF-1 $\beta$ subunits; these two subunits form a heterodimeric protein. The partial pressure of oxygen can regulate the expression of the HIF-1 $\alpha$ subunit; however, HIF-1 $\beta$ is constitutively expressed $(27,28)$. At normal partial pressure of oxygen, HIF-1 $\alpha$ can be hydroxylated by $\mathrm{O}_{2}$ and $\alpha$-ketoglutarate-dependent prolyl hydroxylases. Hydroxylated HIF-1 $\alpha$ can be recognized by the von Hippel-Lindau tumor suppressor protein, which targets HIF-1 $\alpha$ to be degraded via ubiquitination. Therefore, HIF-1 $\alpha$ levels are kept low in the cytoplasm. However, under hypoxic conditions, HIF-1 $\alpha$ cannot be hydroxylated, resulting in accumulation of HIF-1 $\alpha$ in the cytoplasm $(29,30)$. Once the presence of HIF-1 $\alpha$ is stable in the cytoplasm, HIF-1 $\alpha$ can be transported into the nucleus. Subsequently, the two subunits, HIF- $1 \alpha$ and HIF-1 $\beta$, can form a heterodimer. The HIF-1 $\alpha / 1 \beta$ heterodimer can bind to hypoxia-response elements (HREs). HREs exist in hypoxia target genes, and these genes are involved in tumor growth, metastasis, metabolic reprogramming, chemoresistance and radioresistance $(23,24,31)$

It has been reported that HIF-1 $\alpha$ is hyperactivated in TNBC (32). High HIF-1 $\alpha$ levels in cancer tissues are associated with high mortality in several tumor types, including mammary cancer. Furthermore, elevated HIF-1 $\alpha$ levels in the mammary tumor tissues of patients have been associated with high rates of metastasis and mortality (27). The present results showed that fucoidan treatment in highly metastatic TNBC cell lines may inhibit the nuclear accumulation and activation of $\mathrm{HIF}-1 \alpha$.

HIF-1 $\alpha$ is an important transcription factor that can induce the expression of $\sim 40$ genes in hypoxic stromal and cancer cells, including glycolytic enzymes, glucose transporters, erythropoietin, and vascular endothelial growth factors. In addition, HIF-1 $\alpha$ can increase the expression of some genes, and the protein products of these genes can enhance the delivery of oxygen or promote metabolic adaptation to hypoxia, as well as increase metastasis and tumor invasion $(33,34)$.

HIF-1 $\alpha$ can directly or indirectly regulate EMT regulators, and these transcription factors can transactivate EMT-related genes, including $\mathrm{N}$-cadherin, vimentin and E-cadherin $(12,13)$. It has been reported that hypoxia and continuously high levels of HIF-1 $\alpha$ can result in high levels of certain regulators, including TWIST, zinc finger E-box-binding homeobox (ZEB)2, Snail, 
A

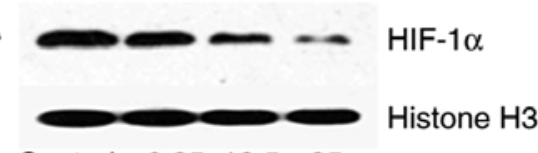

Control $6.2512 .5 \quad 25$

Fucoidan $(\mu \mathrm{g} / \mathrm{ml})$

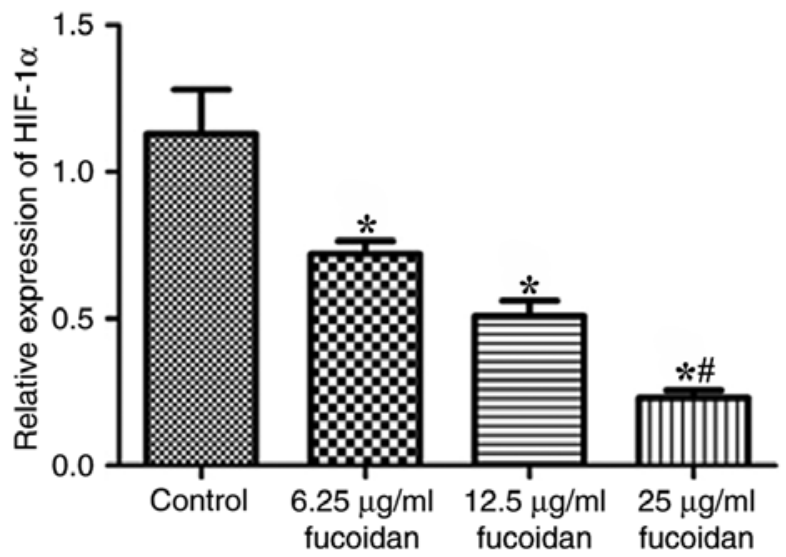

$\mathrm{B}$

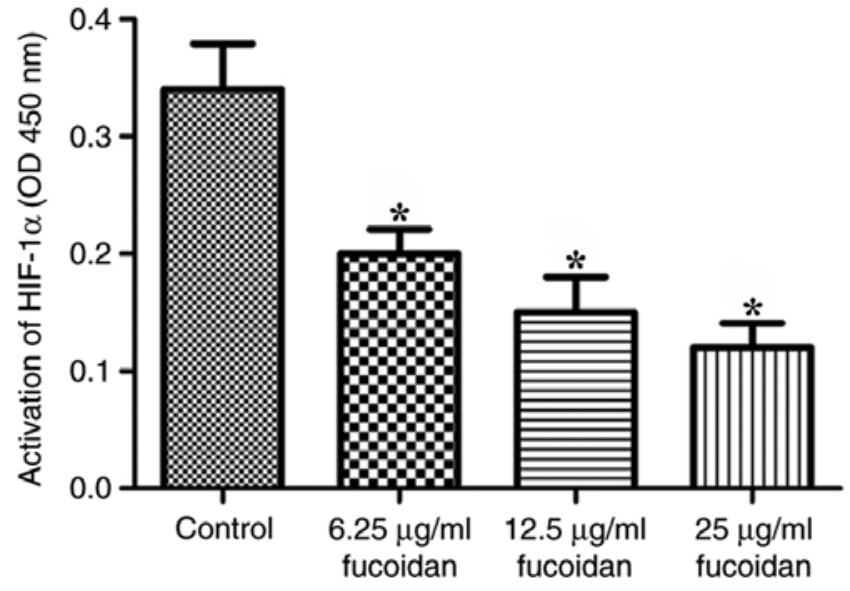

Figure 5. Fucoidan inhibits HIF-1 $\alpha$ protein activation and nuclear accumulation. (A) Effects of fucoidan on the expression and nuclear translocation of HIF-1 $\alpha$ under hypoxic conditions were evaluated by western blotting. Fucoidan treatment inhibited the nuclear translocation of HIF-1 $\alpha$. (B) Activation of HIF-1 $\alpha$ was detected. Fucoidan treatment decreased the activation of HIF-1 $\alpha$. All experiments were repeated three times. Histone H3 was used as a reference for nuclear protein determination. Data are presented as the means \pm standard deviation. ${ }^{*} \mathrm{P}<0.05$ vs. control; ${ }^{*} \mathrm{P}<0.05 \mathrm{vs}$. $6.25 \mu \mathrm{g} / \mathrm{ml}$ fucoidan. HIF-1 $\alpha$, hypoxia-inducible factor- $1 \alpha$.
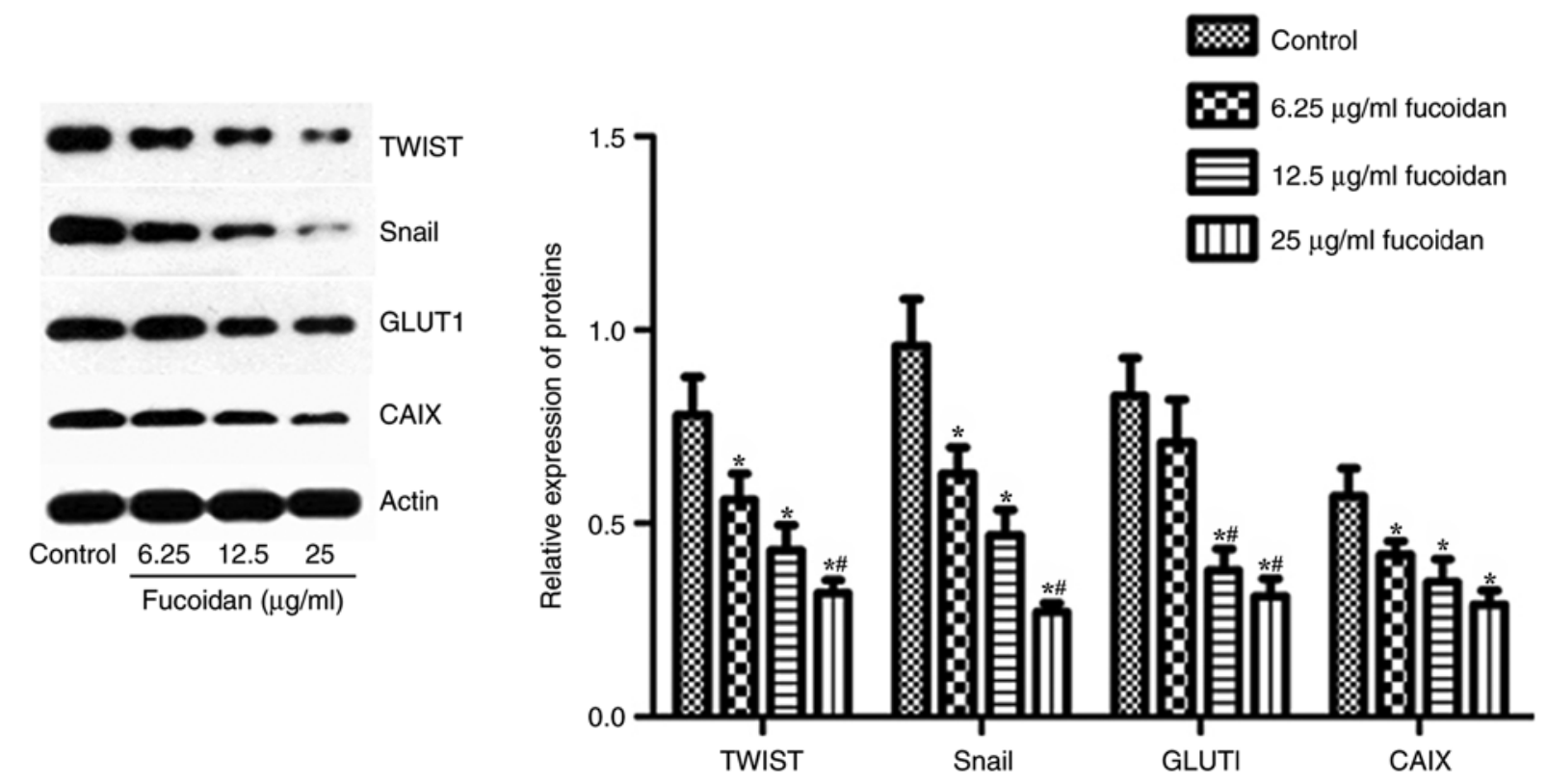

Figure 6. Fucoidan downregulates the protein expression levels of hypoxia-inducible factor-1 $\alpha$ target genes. Western blotting suggested that fucoidan treatment inhibited the expression levels of TWIST, Snail, CAIX and GLUT-1. Data are presented as the means \pm standard deviation. "P<0.05 vs. control; ${ }^{\text {"P }} \mathrm{P}<0.05$ vs. $6.25 \mu \mathrm{g} / \mathrm{ml}$ fucoidan. CAIX, carbonic anhydrase IX; GLUT-1, glucose transporter protein type-1.

transcription factor 3, ZEB1, CAIX and GLUT-1, to moderate EMT and metastasis $(9-11,35,36)$.

TWIST is an important factor that induces EMT and metastasis in cancer. HIF-1 $\alpha$ can directly increase TWIST levels via the response element of HIF1 located in the proximal promoter of the TWIST gene $(9,37)$. TWIST can bind to the E-box in the promoter of E-cadherin and downregulate the expression of E-cadherin (38). Downregulation of TWIST is important for invasion in TNBC (39). Snail is an important target gene of HIF, and overexpression of Snail is involved in EMT. Furthermore, high levels of Snail are associated with highly aggressive types of cancer in humans and mice (40). Snail overexpression is associated with a high rate of metastasis in mammary tumors, whereas Snail silencing decreases the invasiveness and cell motility of mammary cancer (41). 
A

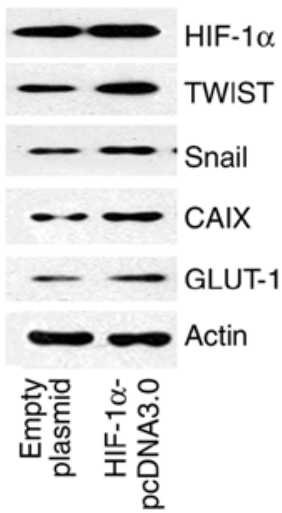

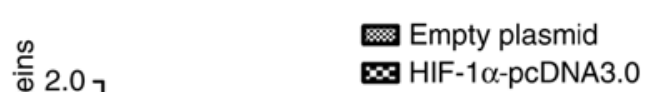

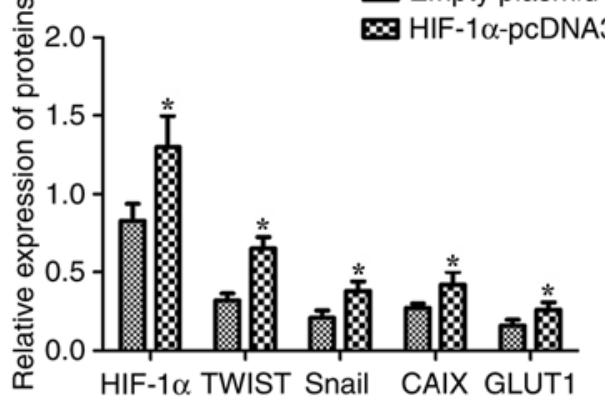

B
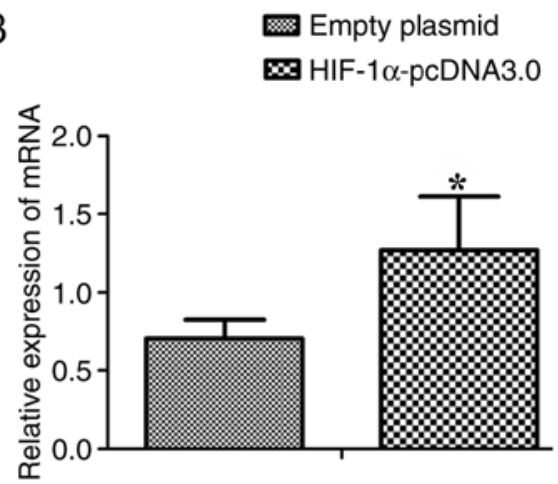

C

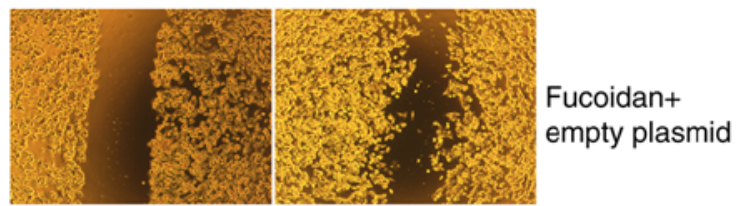

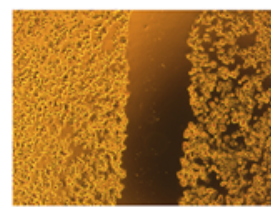

$\mathrm{Oh}$

D

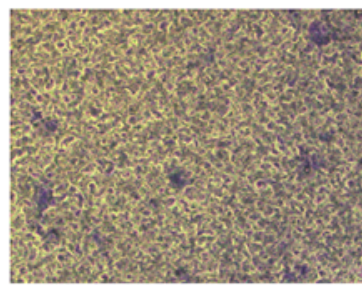

Fucoidan+empty plasmid

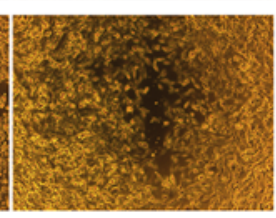

$24 \mathrm{~h}$

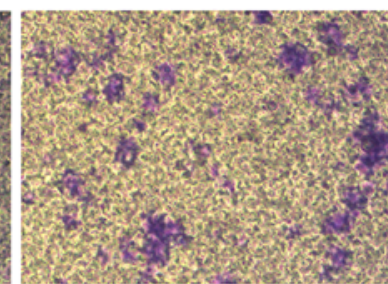

Fucoidan+HIF-1 $\alpha$-pcDNA3.0
Fucoidan+HIF$1 \alpha$-pcDNA3.0
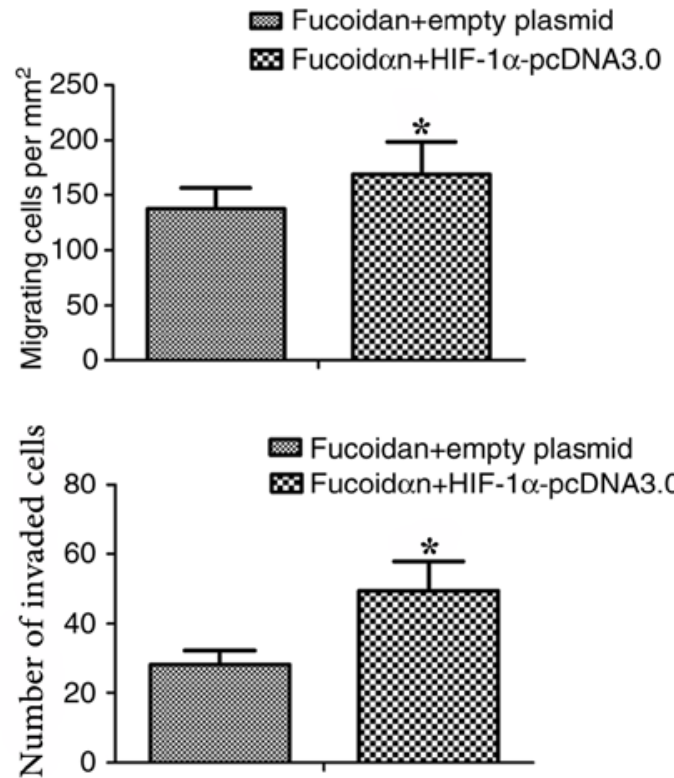

Figure 7. Overexpression of HIF-1 $\alpha$ attenuates fucoidan-mediated suppression of cell invasion and migration. (A) Breast cancer cells were transfected with HIF-1 $\alpha$ overexpression plasmid (HIF-1 $\alpha$-pcDNA3.0). Cell lysates from different groups were prepared and probed for HIF-1 $\alpha$ and its target genes, including TWIST and Snail, through western blotting. (B) HIF-1 $\alpha$ mRNA expression in breast cancer cells was measured by reverse transcription-quantitative polymerase chain reaction. GAPDH was used as s reference. Post-transfection with HIF-1 $\alpha$-pcDNA3.0, the mRNA expression levels of HIF-1 $\alpha$ were increased. Data are presented as the means \pm standard deviation. ${ }^{a} \mathrm{P}<0.05$ vs. empty plasmid. (C) Scratch assay (magnification, $\mathrm{x} 100$ ). (D) Transwell assay (magnification, x200). Breast cancer cells were transfected with HIF-1 $\alpha$-pcDNA3.0 and further treated with $25 \mu \mathrm{g} / \mathrm{ml}$ fucoidan. Migration and invasion of cancer cells were detected after $24 \mathrm{~h}$. Data are presented as the means \pm standard deviation. " $\mathrm{P}<0.05$ vs. fucoidan + empty plasmid. CAIX, carbonic anhydrase IX; GLUT-1, glucose transporter protein type-1; HIF-1 $\alpha$, hypoxia-inducible factor-1 $\alpha$.

HIF-1 can result in metabolic adaptation (or 'reprogramming') to hypoxic and energy-deprived conditions, and can enable tumor cells to survive. HIF-1 upregulates glucose influx through GLUT-1 and increases proton efflux via membranous CAIX. CAIX is involved in the hydration of carbon dioxide to form carbonic acid, which suggests a putative role of this enzyme in the acidification of the tumor environment. A high level of CAIX in patients with mammary cancer has been associated with a short disease-free survival time (42). Hypoxia in tumor tissues can markedly induce the expression of CAIX and has been proposed to be involved in acidification of the tumor microenvironment. In addition, hypoxia can increase cell adhesion and invasiveness. It has been reported that high levels of CAIX are linked to poor prognosis via regulation of the EMT (43). CAIX has the capacity to modulate cell adhesion mediated by E-cadherin through interactions with $\beta$-catenin (44). GLUT-1 levels are positively associated with the expression of vimentin and $\mathrm{N}$-cadherin in tumor tissues but are negatively associated with the levels of E-cadherin. Compared to the survival rates of patients with low levels of GLUT-1, vimentin and $\mathrm{N}$-cadherin, those of patients with high levels of GLUT-1, vimentin and $\mathrm{N}$-cadherin are much lower (45). In the present study, fucoidan treatment decreased the expression of HIF-1 $\alpha$ target genes, including TWIST, Snail, CAIX and GLUT-1, in cells in a hypoxic environment.

The mechanism by which fucoidan downregulates the HIF-1 $\alpha$ signaling pathway will be the next question explored by this research team. In vivo experiments are required to further confirm the effects of downregulation of this pathway on inhibition of migration and invasion. In addition, the present study suggested that HIF-1 $\alpha$ may be a possible novel target for the treatment of TNBC. In animal experiments, we aim to further determine the antitumor effect of fucoidan on 
TNBC, and focus on the preventative and inhibitory effects of fucoidan and its mechanism on tumor metastasis. Once the inhibitory effects and target of action of fucoidan on tumor metastasis have been confirmed and the appropriate dosage of fucoidan has been clarified, further clinical trials may be conducted. This would help to develop fucoidan into a natural antitumor drug.

In conclusion, to the best of our knowledge, the present study identified a novel mechanism by which fucoidan may inhibit EMT and metastasis through the HIF-1 $\alpha$ signaling pathway in mammary cancer. Fucoidan inhibited the activation and nuclear accumulation of HIF-1 $\alpha$. EMT regulators downstream of HIF-1 $\alpha$, including TWIST, Snail, CAIX and GLUT-1, were also downregulated. Subsequently, the expression levels of $\mathrm{N}$-cadherin and vimentin, which are typical markers of EMT, were decreased, whereas the levels of ZO-1 and E-cadherin were increased, leading to the inhibition of EMT and migration in TNBC cells under hypoxic conditions. Therefore, the present study provides novel insight into the mechanisms of fucoidan in mammary cancer treatment.

\section{Acknowledgements}

The authors wish to thank Professor Yinlin Ge and Dr Zheng Zheng (Department of Medicine, Qingdao University, Qingdao, Shandong, China) for their helpful comments and discussion on this study.

\section{Funding}

The present work was supported by the National Nature Science Foundation of China (grant no. 81502298), the Shandong Provincial Natural Science Foundation (grant no. ZR2014JL056), the Qingdao Postdoctoral Application Research Project (grant no. 2015165) and the Qingdao People's Livelihood Science and Technology Project (grant no. 18-6-1-70-nsh).

\section{Availability of data and materials}

The datasets used and/or analyzed during the current study are available from the corresponding author on reasonable request.

\section{Authors' contributions}

MX and HL analyzed and interpreted the data. WL, JZ and TS performed the cell culture, proliferation assay, overexpression of HIF-1 $\alpha$ and examination of protein factors. DX and YL performed migration and invasion assays. MX was a major contributor in writing the manuscript. All authors read and approved the final manuscript.

\section{Ethics approval and consent to participate}

Not applicable.

\section{Patient consent for publication}

Not applicable.

\section{Competing interests}

The authors declare that they have no competing interests.

\section{References}

1. Matsuoka J, Yashiro M, Doi Y, Fuyuhiro Y, Kato Y, Shinto O, Noda S, Kashiwagi S, Aomatsu N, Hirakawa T, et al: Hypoxia stimulates the EMT of gastric cancer cells through autocrine TGF $\beta$ signaling. PLoS One 8: e62310, 2013.

2. Cannito $S$, Novo $E$, Compagnone A, Valfrè di Bonzo L, Busletta $C$, Zamara E, Paternostro C, Povero D, Bandino A, Bozzo F, et al: Redox mechanisms switch on hypoxia-dependent epithelial-mesenchymal transition in cancer cells. Carcinogenesis 29: 2267-2278, 2008

3. Lester RD, Jo M, Campana WM and Gonias SL: Erythropoietin promotes MCF-7 breast cancer cell migration by an ERK/mitogen-activated protein kinase-dependent pathway and is primarily responsible for the increase in migration observed in hypoxia. J Biol Chem 280: 39273-39277, 2005.

4. Tomaskovic-Crook E, Thompson EW and Thiery JP: Epithelial to mesenchymal transition and breast cancer. Breast Cancer Res 11: 213, 2009.

5. Kotiyal S and Bhattacharya S: Breast cancer stem cells, EMT and therapeutic targets. Biochem Biophys Res Commun 453: 112-116, 2014.

6. Majmundar AJ, Wong WJ and Simon MC: Hypoxia-inducible factors and the response to hypoxic stress. Mol Cell 40: 294-309, 2010.

7. Luo D, Wang Z, Wu J, Jiang C and Wu J: The role of hypoxia inducible factor-1 in hepatocellular carcinoma. Biomed Res Int 2014: 409272, 2014.

8. Ji RC: Hypoxia and lymphangiogenesis in tumor microenvironment and metastasis. Cancer Lett 346: 6-16, 2014.

9. Yang MH, Wu MZ, Chiou SH, Chen PM, Chang SY, Liu CJ, Teng SC and Wu KJ: Direct regulation of TWIST by HIF-1alpha promotes metastasis. Nat Cell Biol 10: 295-305, 2008.

10. Tsai YP and Wu KJ: Hypoxia-regulated target genes implicated in tumor metastasis. J Biomed Sci 19: 102, 2012.

11. Lendahl U, Lee KL, Yang H and Poellinger L: Generating specificity and diversity in the transcriptional response to hypoxia. Nat Rev Genet 10: 821-832, 2009.

12. de Herreros AG, Peiró S, Nassour M and Savagner P: Snail family regulation and epithelial mesenchymal transitions in breast cancer progression. J Mammary Gland Biol Neoplasia 15: 135-147, 2010.

13. Evans AJ, Russell RC, Roche O, Burry TN, Fish JE, Chow VW, Kim WY, Saravanan A, Maynard MA, Gervais ML, et al: VHL promotes E2 box-dependent E-cadherin transcription by HIF-mediated regulation of SIP1and snail. Mol Cell Biol 27: 157-169, 2007.

14. Bos R, van der Groep P, Greijer AE, Shvarts A, Meijer S, Pinedo HM, Semenza GL, van Diest PJ and van der Wall E: Levels of hypoxia-inducible factor-1 $\alpha$ independently predict prognosis in patients with lymph node negative breast carcinoma. Cancer 97: 1573-1581, 2003.

15. Wei C, Xiao Q, Kuang X, Zhang T, Yang Z and Wang L: Fucoidan inhibits proliferation of the SKM-1 acute myeloid leukaemia cell line via the activation of apoptotic pathways and production of reactive oxygen species. Mol Med Rep 12: 6649-6655, 2015.

16. Boo HJ, Hong JY, Kim SC, Kang JI, Kim MK, Kim EJ, Hyun JW, Koh YS, Yoo ES and Kwon JM: The anticancer effect of fucoidan in PC-3 prostate cancer cells. Mar Drugs 11: 2982-2999, 2013.

17. Chen H, Cong Q, Du Z, Liao W, Zhang L, Yao Y and Ding K: Sulfated fucoidan FP08S2 inhibits lung cancer cell growth in vivo by disrupting angiogenesis viatargeting VEGFR2/VEGF and blocking VEGFR2/Erk/VEGF signaling. Cancer Lett 382: 44-52, 2016.

18. Yan MD, Yao CJ, Chow JM, Chang CL, Hwang PA, Chuang SE, Whang-Peng J and Lai GM: Fucoidan elevates MicroRNA-29b to regulate DNMT3B MTSS1 axis and inhibit EMT in human hepatocellular carcinoma cells. Mar Drugs 13: 6099-6116, 2015.

19. Xue M, Ge Y, Zhang J, Liu Y, Wang Q, Hou L and Zheng Z: Fucoidan inhibited 4T1 mouse breast cancer cell growth in vivo and in vitro via downregulation of $\mathrm{Wnt} / \beta$-catenin signaling. Nutr Cancer 65: 460-468, 2013. 
20. Xue M, Ge Y, Zhang J, Wang Q, Hou L, Liu Y, Sun L and Li Q Anticancer properties and mechanisms of fucoidan on mouse breast cancer in vitro and in vivo. PLoS One 7: e43483, 2012.

21. Xue M, Ji X, Xue C, Liang H, Ge Y, He X, Zhang L, Bian K and Zhang L: Caspase-dependent and caspase-independent induction of apoptosis in breast cancer by fucoidan via the PI3K/AKT/GSK3 $\beta$ pathway in vivo and in vitro. Biomed Pharmacother 94: 898-908, 2017.

22. Livak KJ and Schmittgen TD: Analysis of relative gene expression data using real-time quantitative PCR and the 2(-Delta Delta C(T)) method. Methods 25: 402-408, 2001.

23. Yang SW, Zhang ZG, Hao YX, Zhao YL, Qian F, Shi Y, Li PA Liu CY and Yu PW: HIF-1 $\alpha$ induces the epithelial-mesenchymal transition in gastric cancer stem cells through the Snail pathway. Oncotarget 8: 9535-9545, 2017.

24. Melillo G: Targeting hypoxia cell signaling for cancer therapy. Cancer Metastasis Rev 26: 341-352, 2007.

25. Hay ED: An overview of epithelio-mesenchymal transformation. Acta Anat (Basel) 154: 8-20, 1995.

26. Lesage J, Suarez-Carmona M, Neyrinck-Leglantier D, Grelet S, Blacher S, Hunziker W, Birembaut P, Noël A, Nawrocki-Raby B, Gilles $\mathrm{C}$ and Polette M: Zonula occludens-1/NF- $\mathrm{B} / \mathrm{CXCL8}$ A new regulatory axis for tumor angiogenesis. FASEB J 31: 1678-1688, 2017

27. Semenza GL: Cancer-stromal cell interactions mediated by hypoxia-inducible factors promote angiogenesis, lymphangiogenesis, and metastasis. Oncogene 32: 4057-4063, 2013.

28. Wang GL, Jiang BH, Rue EA and Semenza GL: Hypoxia-inducible factor 1 is a basic-helix-loop-helix-PAS heterodimer regulated by cellular O2 tension. Proc Natl Acad Sci USA 92: 5510-5514 1995.

29. SalcedaSandCaroJ:Hypoxia-inducible factor 1alpha(HIF-1alpha) protein is rapidly degraded by the ubiquitin-proteasome system under normoxic conditions. Its stabilization by hypoxia depends on redox-induced changes. J Biol Chem 272: 22642-22647, 1997.

30. Semenza GL: HIF-1: Upstream and downstream of cancer metabolism. Curr Opin Genet Dev 20: 51-56, 2010.

31. Shannon AM, Bouchier-Hayes DJ, Condron CM and Toomey D: Tumor hypoxia, chemotherapeutic resistance and hypoxia-related therapies. Cancer Treat Rev 29: 297-307, 2003.

32. Montagner M, Enzo E, Forcato M, Zanconato F, Parenti A Rampazzo E, Basso G, Leo G, Rosato A, Bicciato S, et al: SHARP1 suppresses breast cancer metastasis by promoting degradation of hypoxia-inducible factors. Nature 487: 380-384, 2012.

33. Wigerup C, Påhlman S and Bexell D: Therapeutic targeting of hypoxia and hypoxia-inducible factors in cancer. Pharmacol Ther 164: 152-169, 2016.

34. Finger EC and Giaccia AJ: Hypoxia, inflammation, and the tumor microenvironment in metastatic disease. Cancer Metastasis Rev 29: 285-293, 2010.
35. Peinado H, Olmeda D and Cano A: Snail, Zeb and bHLH factors in tumour progression: An alliance against the epithelial phenotype? Nat Rev Cancer 7: 415-428, 2007.

36. Chu CY, Jin YT, Zhang W, Yu J, Yang HP, Wang HY, Zhang ZJ, Liu XP and Zou Q: CA IX is upregulated in CoCl2-induced hypoxia and associated with cell invasive potential and a poor prognosis of breast cancer. Int J Oncol 48: 271-280, 2016.

37. Chen D, Dang BL, Huang JZ, Chen M, Wu D, Xu ML, Li R and Yan GR: MiR-373 drives the epithelial-to-mesenchymal transition and metastasis via the miR-373-TXNIP-HIF1 $\alpha$-TWIST signaling axis in breast cancer. Oncotarget 6: 32701-32712, 2015.

38. Lopez D, Niu G, Huber P and Carter WB: Tumor-induced upregulation of Twist, Snail, and Slug represses the activity of the human VE-cadherin promoter. Arch Biochem Biophys 482: 77-82, 2009.

39. Montserrat N, Gallardo A, Escuin D, Catasus L, Prat J, Gutiérrez-Avignó FJ, Peiró G, Barnadas A and Lerma E: Repression of E-cadherin by SNAIL, ZEB1, and TWIST in invasive ductal carcinomas of the breast: A cooperative effort? Hum Pathol 42: 103-110, 2011.

40. Cano A, Pérez-Moreno MA, Rodrigo I, Locascio A, Blanco MJ, del Barrio MG, Portillo F and Nieto MA: The transcription factor snail controls epithelial-mesenchymal transitions by repressing E-cadherin expression. Nat Cell Biol 2: 76-83, 2000.

41. Zhang A, Wang Q, Han Z, Hu W, Xi L, Gao Q, Wang S, Zhou J, $\mathrm{Xu}$ G, Meng L, et al: Reduced expression of Snail decreases breast cancer cell motility by downregulating the expression and inhibiting the activity of RhoA GTPase. Oncol Lett 6: 339-346, 2013.

42. Tan EY, Yan M, Campo L, Han C, Takano E, Turley H, Candiloro I, Pezzella F, Gatter KC, Millar EK, et al: The key hypoxia regulated gene CAIX is upregulated in basal-like breast tumours and is associated with resistance to chemotherapy. $\mathrm{Br}$ J Cancer 100: 405-411, 2009.

43. Hyuga S, Wada H, Eguchi H, Otsuru T, Iwgami Y, Yamada D, Noda T, Asaoka T, Kawamoto K, Gotoh K, et al: Expression of carbonic anhydrase IX is associated with poor prognosis through regulation of the epithelial-mesenchymal transition in hepatocellular carcinoma. Int J Oncol 51: 1179-1190, 2017.

44. Svastová E, Zilka N, Zat'ovicová M, Gibadulinová A, Ciampor F, Pastorek J and Pastoreková S: Carbonic anhydrase IX reduces E-cadherin-mediated adhesion of MDCK cells via interaction with beta-catenin. Exp Cell Res 290: 332-345, 2003.

45. Zuo J, Wen J, Lei M, Wen M, Li S, Lv X, Luo Z and Wen G: Hypoxia promotes the invasion and metastasis of laryngeal cancer cells via EMT. Med Oncol 33: 15, 2016. 